\title{
Accountable to who, to whom, for what and how? Unpacking Accountability in Local
} Government Response to Climate Change

\author{
Brett Quayle', Nick Sciulli² \& Elisabeth Wilson-Evered $^{3}$
}

\begin{abstract}
The aim of this exploratory study is to delineate the role of local government in climate change response through an accountability lens. Local governments have an important role in climate change response due to its proximity to the impact the environment will have on its citizens and businesses. Understanding the roles and responsibilities of local government response to climate change, therefore, needs a critical exploration of the ways in which local governments are answerable on its obligations. Local government climate change response was investigated by posing questions aimed to unpack accountability: who, to whom, for what, and how? Findings from the investigation show that climate change response within local councils is a highly contextual phenomenon; where the level of accountability observed is influenced externally by community demands and political cycles, and internally through a hierarchical chain of command, collaboration amongst council workers and the political interests of its leaders. The current study contributes to the literature by deepening understanding of how individuals make sense of organisational initiatives that respond to climate change, as well as highlighting the accountability challenges faced within local governments.
\end{abstract}

JEL classification: M40, Q56

Keywords: Climate change response, Local government accountability, Environmental accounting, Climate leadership, Climate change accountability

\footnotetext{
${ }^{1}$ Corresponding author. PhD Candidate, Victoria University, Melbourne, Victoria, Australia.

Email: brett.quayle1@live.vu.edu.au

${ }^{2}$ Victoria University, Melbourne, Victoria, Australia. Email: Nick.Sciulli@vu.edu.au

${ }^{3}$ Victoria University, Melbourne, Victoria, Australia. Email: Elisabeth.Wilson-Evered@vu.edu.au
} 
Quayle, Sciulli \& Wilson-Evered | Accountable to who, to whom, for what and how?

\section{Introduction}

Local governments have an important role in response to climate change due to their proximity to the effects of environmental events on its citizens and businesses (Fünfgeld \& McEvoy, 2014; van den Berg \& Coenen, 2012; Mees, 2017). However, legislative and regulatory mandates are not yet imposed for local response to climate change, resulting in limited policy making and program implementation (Keskitalo et al, 2016). Local government inaction has been linked with unclear roles and responsibilities (Productivity Commission, 2012), lack of resource building capacity (Sciulli, 2013) and an underdeveloped implementation system (Bache, Bartle, Flinders \& Marsden, 2015).

Response to climate change involves adaptation and mitigation. Adaptation includes taking actions to manage the risks from future climate impacts, care for communities and bolstering the resilience of the economy (Nelson, Adger \& Brown, 2007); whereas mitigation refers to the efforts required to reduce or prevent greenhouse gas emissions (IPCC, 2014). Notwithstanding, its common use, the notion of response to climate change (i.e., both adaptation and mitigation) is conceptually unclear. According to the IPCC's Fourth Assessment Report (2014), adaptation and mitigation policies are one component of larger sustainable development policies; however, given the highly contextualised nature of climate change, substantial overlap exists in identifying whether a specific policy addresses climate change or sustainable development or both. Among, the research and policy gaps concerning climate change strategy there is a lack of systematic attention to the processes and impacts of a gradually changing climate (Head, Adams, McGregor \& Toole, 2014). Also, unclear, are the reasons for the limited response to climate change, although accountabilities within the structures of government are deemed to be fuzzy (Bache et al, 2015). While response to climate change has received considerable theoretical investigation, there is less empirical enquiry on how climate policy is translated into action (Keskitalo, Juhola, Baron, Fyhn \& Klein, 2016).

Understanding the roles and responsibilities of local government response to climate change, therefore, warrants critical exploration of the ways in which local governments are answerable for their actions on climate change (Newell, 2008). To that end, accountability is a concept that emphasises clarity, transparency and collaboration (Schillemans, 2015) and can be useful in generating policy fulfilment and governmental change (Bovens, 2010). Effective accountability is essential for a responsive and responsible government to be answerable on climate change at any level; federal, state, or local (Boston \& Gill, 2011). However, accountability for climate change remains an enigmatic concept, where Hoffman (2016) proposes further empirical enquiry that articulates the measures and dynamics of accountability in its many guises. The aim of the current study, therefore, is to explore local government's role in response to climate change through an accountability lens. Section two presents the literature review and research aims. Section three describes the method and the data collection techniques with local government employees. The study findings are then presented in Section four under a number of key thematic areas. Finally, in Section Five, we discuss the conclusions and recommendations for future research and practice. 


\section{Literature Review}

Gray (1992) argued that the community has a right to information about environmental actions that influence society through the process of accountability. It is not enough to simply say that local government manages climate change, where important questions need to be answered, such as responsible for what, to whom and through what means (MacDonald, 2014). Accountability is a process that involves the explanation and justification of actions of an actor to a forum which in turn passes judgement on these actions and consequences are placed on the actor (Bovens, 2007). Negative sanctions are then imposed by external forces on public officials who violate certain rules of conduct (Schedler, 1999), where consideration of the contextual factors or mechanisms that define these accountability relationships is also important (Akpanuko \& Asogwa, 2013).

As a means of applying this conception of accountability to democratic and institutional settings, Mulgan (2003) devised a framework containing key dimensions of accountability and are answered via four questions. The first question - who is accountable - seeks to identify those responsible, whether that is the individual actions of a leader, or through the collective actions of an organisation or agency. To whom, secondly, aims to identify the accountholders to whom accountability is owed. Articulating for what is to be held to account is the third question and focuses on the duties to be carried out, which for example may be a contract or performance goals. The final question asks how the agent will be accountable and includes accurate information that must be filtered through collaboration and discussions amongst stakeholders (Brandsma \& Schillemans, 2014). However, empirical evidence in support of the concept of public accountability within the context of climate change has been minimal (Greiling \& Halachmi, 2014).

Current methods of accountability are not conducive to addressing local government response to climate change as there is a focus on monitoring and enforcing existing functions and processes into existing organisational objectives that do not prioritise environmental objectives (Kramarz \& Park, 2016). The primary function of local government is seen by many to service the needs of the community and to enact rules mandated by state and federal levels of government (Kloot \& Martin, 2010). Current accountability mechanisms related to responding to climate change focus predominantly on financial outcomes and emissions reporting which has been shown to not effectively encapsulate environmental impacts or assist in reducing emissions (Jarvis, 2014; Milne \& Grubnic, 2011). Further, the demands for information on performance placed on local governments by external stakeholders of authority may result in reactive decision making (Agyemang and Ryan, 2013), which is not conducive to the long-term planning that is required for an effective response to climate change (Fünfgeld \& McEvoy, 2014). It is clear that current accountability practices are not resulting in advancement of environmental initiatives (Hoffman, 2016).

Combining both environmental and economic performance within accounting practices, however, is a possible means of addressing these shortcomings (Gibassier \& Alcouffe, 2018). Thomson, Grubnic and Georgakopoulos (2014) proposed that when linking environmental and accounting practices, local governments must address how these practices are defined and embedded into existing processes. Further, local governments must examine the methods that are developed and used to embed these practices. Embedding environmental initiatives across organisations may be 
Quayle, Sciulli \& Wilson-Evered | Accountable to who, to whom, for what and how?

a way forward in determining response to climate change in local governments and several solutions are suggested, through organisation-wide collaboration, reviewing existing policies and plans, tailored communication and senior management support (Zeemering, 2018). Local government response to climate change requires conceptual clarity and warrants a pluralistic discourse through the lens of social and environmental accounting research, particularly in the realm of what it means to be accountable for climate change (Lehman \& Kurrupu, 2017).

Accountability has typically been troubled by definitional and measurement specificity, especially in the context of climate change. This term is often used interchangeably with other environmental initiatives such as sustainability (IPCC, 2014). Recently, Mees and Driessen (2018) proposed five key accountability mechanisms of local climate change adaptation and examined this empirically through an interactive local governance arrangement (i.e. the design and implementation of a multi-functional dike). Based on interviews with key project planners, the authors emphasised the importance of having responsibilities and authority clearly articulated, checks and sanctions (e.g., performance standards and reporting), political oversight, citizen engagement, and transparency (e.g., access to information on the decision-making process and outcomes). These mechanisms, however, were not sustained throughout the arrangement and tapered off during the project implementation phase but were somewhat remedied by the 'informal' mechanisms of trust, relationship building and the political acumen of its leader. Although the findings offer valuable insights into potential public accountability mechanisms, the case study focused on a setting where response to climate change was the key driver of the arrangement and whose citizens were actively involved in the process. Further research is required to examine whether similar accountability mechanisms are observed in local government settings in which response to climate change is not the primary driver in decision making.

Social and environmental accounting research within the public sector is limited (Gray, Adams \& Own, 2014) and requires innovative approaches when tackling issues like response to climate change which must extend beyond a business-centric focus (Lehman \& Kuruppu, 2017; Parker, 2011). The limited research on public accountability and response to climate change has mostly focused on the content that was reported, without examining how this information is embedded within the organisation, how it was evaluated or how it facilitated further discussions and action amongst decision makers. The reporting and sharing of information are only one element of accountability, where other considerations must be made and have rarely been investigated empirically (Brandsma \& Schillemans, 2014). Further, Bernauer and colleagues (2016) postulate that the involvement of citizens on social issues such as climate change can have an impact on the accountability of government institutions within different contexts.

The primary purpose of this research, therefore, is to offer a preliminary investigation of how response to climate change within local government is articulated within the context of public accountability. The current research responds to calls to keep climate change accounting research interesting and different (Milne \& Gubnic, 2011) with a need to examine the organisational processes of accountability (Bebbington \& Larrinaga, 2017) and the roles and responsibilities of stakeholders in the absence of climate change regulation (Lewis \& Russell, 2011). The current study will examine how key questions about accountability - who, for what, to whom and how (Mulgan, 2003) - are answered in the context of local government response to climate change. 


\section{Methods}

\subsection{The Study}

This research is exploratory and, as such, provides empirical observations that contribute to a deeper understanding of the nexus between response to climate change and accountability within local government (Lehman \& Kuruppu, 2017). As accountability is an evolving and complex concept (Mulgan, 2000), a qualitative approach through interviews offers a deeper understanding in the current research (Yin, 1994). Climate response is a complex phenomenon and warrants an investigation that considers the individual situated accounts of this phenomena in different social contexts, where a localist perspective will be adopted (Qu \& Dumay, 2011).

Considerations of how individuals within organisations make sense of climate change can help deepen understanding of how organisations enact these initiatives (Perey, 2013). A range of stakeholders other than key decision makers and managers were selected to participate in the study, reflecting calls by Parker (2011) to include multiple voices as a way of expanding the process of social and environmental accounting research. Furthermore, this research sought the views of stakeholders with varying levels of seniority (i.e. both senior and junior level public servants) to enrich understanding of hierarchical accountability interactions (Jarvis, 2014). Last, public servants from different areas provided opinions about how response to climate change is embedded throughout their organisation.

\subsection{Context}

Australian coastal regions are prone to the effects of climate change through rising sea-levels, storms and coastal erosion (Head et al, 2014). In Australia, government is structured across three levels: federal, state and local. The State of Victoria, which was identified as Australia's third large emitter of fossil fuels has an emissions reduction target of 15-20\% below 2005 levels and net zero by 2050 , as well as a renewable energy target of $25 \%$ by 2020 and $40 \%$ by 2025 (Climate Change Authority, 2019). Despite these targets, a 2018 report outlining Australia's environmental condition was worsening, including an increase in temperatures, a decline in rainfall, poor vegetation growth and destruction of vegetation and ecosystems through drought, fire and land clearing (Van Dijk, 2019).

\subsection{Sampling}

Due to the exploratory nature of the current study, a convenience sampling technique was used to recruit participants (Anderson, 2010). Representatives from 25 local government areas in Victoria, Australia were approached to participate in the study. Each person was advised of the research aims; specifically, that the project would examine (a) what it means for local government areas in Victoria to be accountable for climate change, and (b) the organisational structure of local government areas and the processes involved in community engagement. Following informed consent, interviews were conducted in-person or over the telephone, were recorded and was of 30 to 60 minutes in duration. Between November 2017 and February 2018, individual and group interviews were conducted with 33 public servants from six councils. Respondents ranged in level of seniority and from varying departments (Table 1). 
Quayle, Sciulli \& Wilson-Evered | Accountable to who, to whom, for what and how?

Table 1. Participant demographics

\begin{tabular}{ll}
\hline & Number \\
\hline Actor group & 5 \\
Executive & 9 \\
Management & 8 \\
Coordinator & 11 \\
Officer & 12 \\
Departmental group & 8 \\
Natural environment & 5 \\
Planning & 4 \\
Strategy and performance & 3 \\
Infrastructure and Built environment & 3 \\
Corporate & 1 \\
Administration & \\
\hline
\end{tabular}

\subsection{Procedure}

Ethical approval was obtained for the research from the University Human Research Ethical Committee. Interviews were semi-structured, which is a method useful to elicit detailed responses for the broad themes that cover complex phenomena (Fowler, 2013). Several types of questions were employed, including direct, indirect, probing, interpreting and follow-up questions. Example of interview questions included:

- Describe the ways, if any, in which climate change initiatives are embedded within the council (Thomson et al, 2014)?

- How do citizens hold your council to account on response to climate change (Bernauer et al, 2016)?

- What accountability mechanisms does your council have in relation to response to climate change (Mees and Driessen, 2018)?

The semi-structured interview format is also pertinent in research where the focus is on extracting local perspectives based on the individual's unique social context (Qu \& Dumay, 2011), as well as capturing the individual sensemaking of environmental initiatives within organisations (Perey, 2013).

\subsection{Analysis}

Interview recordings were initially transcribed and entered into the N-Vivo computerised data management program. The interview responses were examined using the principles of thematic analysis; where the data was coded using both inductive (i.e. themes derived by the content of the data) and deductive (i.e., concepts of accountability were used to interpret the data) approaches (Braun, Clarke, Hayfield \& Terry, 2019). Given the aim of the research was to gain a deeper understanding of local government accountability for response to climate change, both approaches were used so as to maximise knowledge-building. Coding interview data involves a degree of sensemaking and was facilitated by the development of a codebook to analyse the data (DeCuirGunby, Marshall and McCulloch, 2011). This codebook was articulated in the present study through a systematic six-stage process of thematic analysis that is useful to demonstrate rigour for both inductive and deductive theme development (Fereday \& Muir-Cochrane, 2006). The six stages involved: (a) code manual development, (b) reliability testing, (c) identification of initial 
themes and data summation, (d) applying codes to text, (e) identification of themes and connection of codes, and (f) corroborating and confirming the coded themes.

\section{Results}

The following themes were derived from the analysis of the interviews and provide empirical context surrounding accountability within local councils. As a means of unpacking accountability in the context of local government response to climate change, the themes derived from the interviews were organised to answer Mulgan's (2003) four questions of accountability.

\section{a. Who is (are) accountable?}

\section{Unclear roles and responsibilities}

The councillors and organisation directors are the chief decision makers and accountable for actions taken within local government. All the local governments follow a similar hierarchical structure, whereby the elected councillors and directors in charge of decision making. However, the responsibilities associated with response to climate change were mostly delegated to the environment teams, as well as through collaboration with external agencies and consultants on specific projects.

The strategic focus of local council influences how roles and responsibilities are assigned within the council's organisational structure regarding response to climate change. Several respondents noted that initiatives in response to climate change were viewed as an additional action to the primary function of service delivery, and most staff did not have any capacity to undertake additional tasks. To a large extent, this situation has been influenced by organisational restructures within each council but also because there is the perception of a conservative organisational culture resistant to innovation and change. Also present was the potential for ambiguity over responsibilities on response to climate change, which is linked to the issue of governance:

I'm not really sure who's in charge of how to manage climate change... It is a governance issue, a lot of people care a lot and have the technical skills, but how does that filter into a good decision (Officer, Infrastructure and Built environment).

This finding reflects the challenges associated with assigning accountability for collective outcomes (Mulgan, 2003) which has previously been described as the problem of many hands (Bovens, 2007).

\section{Green leaders}

Respondents noted that commitment to environmental initiatives from councillors could influence how much a council focuses on response to climate change, and this was more common in jurisdictions whose citizens and councils advocated for a greater emphasis on environmental initiatives. The commitment of its leaders was viewed by some respondents as generally symbolic and informed the strategic direction of the council. However, environmental initiatives were not a priority for the councillors in some councils, and so less emphasis was placed on response to 
Quayle, Sciulli \& Wilson-Evered | Accountable to who, to whom, for what and how?

climate change. For one council where response to climate change was not a priority, there was only one employed environment officer who spoke of the struggles in creating meaningful change within the council.

\section{Third-party stakeholders}

Collaborative working groups and advisory committees were also evident in most councils and include representatives such as councillors, council staff and community members. On occasions where response to climate change was evident, local councils tended to collaborate with external partners such as contractors and other councils where guidance from state and federal levels of government - or even the councillors within council - was absent. The use of third-party consultants was often seen as a better alternative to using internal staff from the perspective of decision makers as doing so gave credence to the process:

My team uses consultants, technical experts, I'm the one accountable for the output, not them. I think it gives people the flexibility to use people when you need to, a different expert for a slightly different thing. You'd get better outcomes, current knowledge (Executive, Environment).

\section{b. Accountable to whom?}

\section{External accountholders}

Local councils are under the scrutiny of the public, which as one respondent noted, is an implied example of accountability. Respondents commented that local governments also had to adhere to legislative and regulatory requirements as mandated by state governments. Nearly all respondents reported that the primary aim of local councils is to service the needs of the community. However, the actions that are necessary for an effective response to climate change are not generally aligned with the immediacy of community demand. Respondents suggested that citizen demands were generally highly specific and localised (e.g., rubbish collection), though several respondents noted that they felt the community was generally apathetic toward large and complex issues like climate change:

The voters want immediate, the here and now and I think to some extent the community they just assume the council can deal with climate change. They don't want to know, council's responsibility, council will sort it out. (Coordinator, Infrastructure and Built environment).

Despite the perception of community apathy by the councils, a small pocket of residents in each community advocated strongly for action on climate change which was only sometimes successful:

There are small groups with the community who, when they can get themselves organised, can make life difficult for council by involving the media in certain campaigns around what council is or is not doing. (Executive, Corporate services). 
The socioeconomic status of residents was also cited by several respondents as a factor relating to how citizens engage with council, noting that affluent residents tended to have greater means of holding councils to account.

\section{Internal accountholders}

Local councils exist in a political landscape and, as such, are constrained by election cycles, governmental bureaucracy and a hierarchical leadership structure. Within this political context exists a hierarchical chain of command, where several actions are mandated from higher levels of the organisational hierarchy and approval or sign-off is required. A great deal of legislative requirements exists within local councils, though mandates concerning response to climate change were described as less clear. Some respondents noted that, while the hierarchical structure restricted what can and can't be done, a few local councils still pursued response to climate change initiatives. For instance, the environment departments had developed workarounds for environmental initiatives even when there was no mandate by the senior leadership team or councillors, particularly when no approval or sign-off was needed.

\section{c. Accountable for what?}

\section{Unclear outputs}

The enormity of climate change has created challenges for local governments in terms of articulating what accountability looks like. While there were differences in the level of response to climate change between the councils in the current study, respondents mentioned that local governments were constrained by unclear guidance from state and federal levels of government, minimal funding and were overburdened by service delivery demands. Articulating what councils were accountable for in terms of response to climate change was less clear due to an overload of service commitments:

I think we are good at developing plans, of doing stuff, we're really good at that, but we're not necessarily good at matching the resource to the plan and the measures of the outcome in a sort of coherent way. We try and do too much across a whole range of areas and we don't have the resources to deliver on that, so we over promise and under-deliver (Executive, Corporate).

\section{Community demands}

Respondents explained that the demands of the community dictate the decisions made, where other issues often take precedence over council's response to climate change:

(Climate Change) is always an interesting one, people want to look after the environment and have lots of lovely trees, but they want to be able to park their car outside their house and shopping centre (Executive, Strategy and Performance). 
Quayle, Sciulli \& Wilson-Evered | Accountable to who, to whom, for what and how?

One respondent noted that there is a tendency to avoid making decisions that may be perceived as being unpopular by the community, which has affected response to climate change:

It's a complex thing to respond to because if you say to them, we'll put up rates $20 \%$ and we're going to do this and that, we'll be carbon neutral as a municipality by 2020, they're not going to want to do that. (Management, Corporate Performance)

\section{Council strategy}

Most respondents had stated that there was a formal document outlining the environmental strategy of the council, though some of these documents at the time of the interviews were still in development or being updated. The strategy documents outline the obligations set out by the local council to the community it represents. This document was council's way of providing information regarding decisions on its strategic direction in a specified period, as well as outlining the actions that will be taken to address these decisions. Although this document was considered essential in driving actions throughout the councils, the level of detail as it pertained specifically to climate change varied between the councils. Climate change is a term that is often used within the umbrella term sustainability and, even though some of the projects that are enacted are indirectly related to climate change, the term climate change is only featured in generally high-level strategic documents. As financial savings tend to be favoured, environmental outcomes are largely seen as having peripheral benefits, which is reflective of previous findings (Jarvis, 2014; Milne \& Grubnic, 2011).

\section{Advocacy}

Respondents commented that the role of local council in responding to climate change is in advocating for action in the upper tiers of governments, ratepayers and with private enterprises. Within these parameters, however, some action on climate change was occurring:

The thing that we can do is advocate, this becomes an advocacy role and these issues are important to our community. We don't see other levels of government responding to these and we harness some of the energy of the community to produce a different sort of outcome (Executive, Strategy and Performance).

\section{d. How are they accountable?}

\section{Reporting}

Each council reports on its performance through the actions that are outlined in the council plan. Several respondents noted that reporting on the progress of actions was a clear account of how the council was progressing towards its obligations and was particularly useful for articulating financial objectives. Although all councils did report on its carbon emissions, reporting on other aspects of environmental performance was less clearly defined. For instance, one respondent noted the struggle in quantifying an action that focused on climate change adaptation: 
I spoke with a few people in the organisation that had ties with people that work in local manufacturing and farming and just made some pretty rudimentary comment on it about that we were aware that local animal livestock industries were insulating their sheds to keep animals more comfortable as an adaptation measure. Then I marked 50\% complete and whatever the date was and that was that (Officer, Planning).

Most respondents had stated that the methods used to measure response to climate change either lacked operational specification or was non-existent, where it was difficult to determine if the actions were beneficial. Additionally, the level of information pertaining to strategy implementation varied between councils. The councils that had focused on embedding climate change into the rest of the organisation tended to have more clearly defined strategic direction. How the information is communicated through these documents tended to influence how these actions were undertaken:

I guess some of those high-level documents in the past when they're addressing climate change or where've got an environment strategy, that's been nested in just a small unit of responsibility and it's how it gets taken up by the broader organisation (Officer, Strategy and performance).

The targets that some of the councils set itself appeared to be highly aspirational and focused on carbon neutrality and emissions reduction targets, though respondents stated that each of their respective councils were struggling to reach these self-imposed targets. Councils may be struggling to reach these targets due to a lack of regulation surrounding actions that respond to climate change (Keskitalo et al, 2016). Although some councils had the capacity to act, there was no legal mandate to do so.

\section{Community consultation}

Much of the strategy that guides the council objectives is derived through community consultation, which informs the direction that the council will take. There was evidence of public forums in all councils where citizens are given the option to engage with the council, though the topic of climate change was seldom addressed:

The experience is you get cross examined in public, and you get held to account... If something's happening, we're building a new road for example, it's very likely a councillor or active member of the public will query them (Executive, Natural Environment).

According to Mulgan (2003), however, community consultation is at the discretion of those choosing to consult and is not the same as accountability which involves an obligation to respond to citizen demands.

\section{Reactive decision-making}

Although respondents spoke of the necessity of holding a political position and to not be swayed by short-term and reactive decision-making for effective leadership, the opposite was more evident. Stated on multiple occasions was that many of the decisions made within local government were based on managing public perception. Respondents suggested that actions 
Quayle, Sciulli \& Wilson-Evered | Accountable to who, to whom, for what and how?

perceived to be in response to climate change (e.g., solar panels on government buildings) were partly based on demonstrating action to the community. Many respondents reported that local councils are structured in such a way that decisions are based on meeting immediate community demands, which is problematic in the realm of the long-term nature of climate change.

Despite the foregoing observations, the commitments made by councillors and stated in formal documents such as council plans and annual reports imply that the councillors will be held accountable for their actions by the public. However, effective leadership on long-term and systemic issues like climate change are compromised by the short-term political cycles.

\section{Embedding response to climate change}

While responsibilities concerning response to climate change were not always clearly defined, several respondents noted that the level of collaboration amongst staff within the organisation was related to innovative approaches aimed at addressing sustainability initiatives. Also evident was that there was more collaboration in some councils, where this was due to building relationships through effective communication and an ability to demonstrate political stewardship through negotiation and strategic influence. Another key factor was having adequate infrastructure and systems to support collaboration. One council had embedded environmental considerations into its procurement process, where other departments were made to consider the environmental option. For another council, this approach involved embedding climate change thinking into the council's business as usual activities. These findings reflect previous literature that highlights the importance of embedding response to climate change across the whole organisation (Thomson et al, 2014).

While there are examples of innovative ways of addressing climate change through internal collaboration within each council, there were several observations of a silo culture that inhibited innovation:

We have a very passive culture, which is really typical of local government... but if we want to be adaptable and innovative and lead change, it's almost contrary to what our culture is (Coordinator, Strategy and performance).

For the most part, any actions that need to be completed relating to climate change are dealt with by the environment department, even though this is not always clearly articulated in the strategic plan. The capacity for service delivery within local councils is restrictive, and initiatives that are a response to climate change are generally viewed as less important in comparison to immediate concerns by both the public and decision makers. However, most councils do provide some programs that focus on environmental education and behaviour change. Respondents noted that in their programs, more familiar language that is subject-specific and tangible (e.g. reducing electricity bills) is often used in favour of the term climate change.

\section{Discussion and Conclusions}

The aim of the current investigation was to examine how response to climate change within local government is articulated within the context of public accountability, following on from calls to examine how local governments are answerable on responding to climate change (Newell, 2008). 
Response to climate change within local councils is a highly contextual phenomenon; where the level of accountability observed is influenced externally by community demands and political cycles, and internally through a hierarchical chain of command, collaboration amongst council workers and the political interests of its leaders. Within the realm of the local government, the councillors and chief executive offer are the individuals that are ultimately responsible for the actions taken. The Australian context of the current investigation has also shown that response to climate change exists in a political context of uncertainty with little to no regulatory framework to guide this process.

The current study contributes to the literature by deepening understanding of how individuals make sense of organisational initiatives in response to climate change (Perey, 2013), as well as highlighting the accountability challenges faced within local governments. For most of the councils that were investigated, information pertaining to response to climate change is predominately shared through its strategy documents. Despite existing research highlighting issues associated with the breadth and accuracy of emissions reporting (Milne \& Grubnic, 2011), most councils were reporting on carbon emissions and taking steps to reduce its carbon footprint. While there was no external mandate to report such information, by doing so councils acted on selfimposed objectives stated in their strategic planning documents. Aside from emissions reporting, the degree to which information on response to climate change was embedded within council objectives varied considerably and was determined by many factors that drove action or inaction (e.g. a siloed culture). The current findings support existing research emphasising the importance of embedding climate actions throughout the organisation (Gibassier \& Alcouffe, 2018).

Several respondents spoke of the detailed process involved in developing strategic documents, however, the development of a strategy in of itself is not a milestone, rather it is the starting point toward fulfilling council objectives. Some council staff noted that the emissions targets were more aspirational than they were realistic; however, there was considerable ambiguity about how these actions were implemented, measured and evaluated. The execution of strategy can be problematic, particularly when the measurable outcomes are poorly defined (Christensen \& Lægreid, 2015). This situation was also conflated by the notion that climate change is traditionally dealt with by the environment department and whose scope was limited in the degree to which actions were integrated throughout the council. Therefore, current response to climate change within councils is acknowledged as an important focus, though understanding for what, to whom and through what means is in its infancy (MacDonald, 2014).

Local councils are, by and large, held to account by the community which is reflected by the degree to which citizens are involved with the development of council strategy through consultation. Though, as Mulgan (2003) highlighted, consultation is not a demonstration of accountability. Structural mechanisms within local government only allow for short-term and reactive decision making and is contrary to the requirements on climate action (Fünfgeld \& McEvoy, 2014). Minimal action by local councils may also reflect a lack of understanding of what constitutes response to climate change, which in turn is partly influenced by unclear parameters that enable action. However, some councils have found that environmental projects have more success when they have been able to demonstrate clear financial outcomes as the primary benefit, while environmental or social outcomes are viewed as an additional benefit. Previous research has also highlighted the need to reframe the language associated with environmental reporting to terms 
Quayle, Sciulli \& Wilson-Evered | Accountable to who, to whom, for what and how?

such as operational efficiency, and to include both direct and indirect emissions (Sullivan \& Gouldson, 2013).

This investigation reveals that accountability is partly determined by the effectiveness of policy implementation through localised language within local councils. As a concept, climate change may be suited for high-level documents and planning, but further down the hierarchy, simpler language is warranted in the implementation of strategy. Climate change initiatives within councils may be more successful when the messaging uses familiar language and some form of financial benefit when advocating for change by decision makers within the council, but also more broadly with state government, other organisations and with the community. A lack of specific and transparent information on response to climate change, in addition to resource constraints and no required mandates suggest that local councils are unable - or unwilling - to hold their institutions accountable in terms of demonstrable action on climate change, aside from tokenistic and selfsustaining actions that manage the councils' public reputation. 


\section{References}

Agyemang, G \& Ryan, B 2013, 'Accountability and Performance Management Systems within Private and Public Sector Organisational Change Processes', in CR Lehman (ed), Managing Reality: Accountability and the Miasma of Private and Public Domains (Advances in Public Interest Accounting, Vol. 16), Emerald Group Publishing Limited, pp. 1-38. https://doi.org/10.1108/S1041-7060(2013)0000016004

Akpanuko, E \& Asogwa, I 2013, 'Accountability: A Synthesis', International Journal of Finance and Accounting, vol. 2, no. 3, pp. 164-173.

Anderson, C 2010. 'Presenting and Evaluating Qualitative Research', American Journal of Pharmaceutical Education, vol. 74, no. 8, 1-7. https://doi.org/10.5688/aj7408141

Bache, I, Bartle, I, Flinders, M \& Marsden, G 2015, 'Blame Games and Climate Change: Accountability, Multi-Level Governance and Carbon Management', The British Journal of Politics and International Relations, vol. 17, pp. 64-88. https://doi.org/10.1111/1467-856X.12040

Braun, V, Clarke, V, Hayfield, N, \& Terry, G 2019, 'Thematic analysis'. In P Liamputtong (ed), Handbook of Research Methods in Health Social Sciences, Springer, Singapore, pp. 843-860. https://doi.org/10.1007/978-981-10-5251-4_103

Bebbington, J \& Larrinaga, C 2014, 'Accounting and global climate change issues'. In J Bebbington, J Unerman, \& B. O'Dwyer (eds), Sustainability Accounting and Accountability, London, Routledge, pp. 199-212.

Bernauer, T, Gampfer, R, Meng, T \& Su, Y 2016, 'Could more civil society involvement increase public support for climate policy-making? Evidence from a survey experiment in China', Global Environmental Change, vol. 40, pp.1-12. https://doi.org/10.1016/j.gloenvcha.2016.06.001

Boston, J \& Gill, D 2011, Joint or Shared Accountability: Issues and Opinions, Institute of Policy Studies Working Paper, viewed 18 August, $<$ http://researcharchive.vuw.ac.nz/handle/10063/2591>.

Bovens, M 2007, 'Analysing and Assessing Accountability: A Conceptual Framework', European Law Journal, vol. 13, no. 4, pp. 447-468. https://doi.org/10.1111/j.1468-0386.2007.00378.x

Bovens, M, Goodin, RE \& Schillemans, T 2014, The Oxford Handbook of Public Accountability, Oxford University Press, Oxford. https://doi.org/10.1093/oxfordhb/9780199641253.013.0012

Brandsma, GJ \& Schillemans, Y 2012, 'The Accountability Cube: Measuring Accountability', Journal of Public Administration Research 
Quayle, Sciulli \& Wilson-Evered | Accountable to who, to whom, for what and how?

and Theory, vol. 23, no. 4, pp. 953-975.

https://doi.org/10.1093/jopart/mus034

Christensen, T \& Lægreid, P 2014, 'Performance and Accountability-A

Theoretical Discussion and an Empirical Assessment', Public

Organization Review, vol. 15, no. 2, pp. 207-225.

https://doi.org/10.1007/s11115-013-0267-2

Climate Change Authority 2019, Australia's climate change policies at the Australian and state and territory government levels, Commonwealth of Australia, viewed 12 August, $<$ http://climatechangeauthority.gov.au/authority-releases-itsstocktakes-australian-and-international-climate-change-policies $>$.

Commonwealth of Australia 2009, Climate Change Risks to Australia's Coasts: A First Pass National Assessment, Commonwealth of Australia, viewed 12 January, $<$ https://www.environment.gov.au/climatechange/adaptation/publications/climate-change-risks-australiascoasts $>$

DeCuir-Gunby, JT, Marshall, PL, \& McCulloch, AW 2011, 'Developing and using a codebook for the analysis of interview data: An example from a professional development research project', Field Methods, vol. 23, no. 2, pp. 136-155. https://doi.org/10.1177/1525822X10388468

Fereday, J \& Muir-Cochrane, E 2006, 'Demonstrating Rigor Using Thematic Analysis: A Hybrid Approach of Inductive and Deductive Coding and Theme Development', International Journal of Qualitative Methods, vol. 5, no. 1, pp. 80-92. https://doi.org/10.1177/160940690600500107

Fowler, FJ 2013, Survey research methods, Thousand Oaks, California. Fünfgeld, H. \& McEvoy, D 2014, Framing Climate Change Adaptation in Policy and Practice (VCCCAR Project: Framing Adaptation in the Victorian Context), viewed January 12, http://www.vcccar.org.au/publication/working-paper/framing-climatechange-adaptation-in-policy-and-practice

Gibassier, D \& Alcouffe, S 2018, 'Environmental Management Accounting: The Missing Link to Sustainability?' Social and Environmental Accountability Journal, vol. 38, no. 1, pp. 1-18. doi:10.1080/0969160X.2018.1437057 https://doi.org/10.1080/0969160X.2018.1437057

Gray, R 1992, 'Accounting and Environmentalism - an exploration of the challenge of gently accounting for accountability, transparency and sustainability, Accounting, Organisations and Society, vol. 17, no. 5, pp. 399-425.

https://doi.org/10.1016/0361-3682(92)90038-T

Gray, R, Adams, CA, \& Owen, D 2014, Accountability, social responsibility, and sustainability: accounting for society and the 
environment, Pearson Education Limited, Harlow, viewed 19

February 2017, http://hdl.handle.net/123456789/1262

Greiling, D. \& Halachmi, A 2013' Accountability and Organizational Learning in the Public Sector', Public Performance \& Management Review, vol. 36, no. 3, pp. 380-406.

https://doi.org/10.2753/PMR1530-9576360301

Head, L, Adams, M, McGregor, H \& Toole S 2014 'Climate change and Australia', Wiley Interdisciplinary Reviews: Climate Change, vol. 5, no. 2 , pp. 175-197. https://doi.org/10.1002/wcc. 255

Hoffman, M 2016, 'The Analytic Utility (and Practical Pitfalls) of Accountability', Global Environmental Politics, vol. 16, no. 2, pp. 2232 .

https://doi.org/10.1162/GLEP a 00351

Intergovernmental Panel on Climate Change 2014, Climate Change 2014: Synthesis Report. Contribution of Working Groups I, II and III to the Fifth Assessment Report of the Intergovernmental Panel on Climate Change, viewed 18 July 2016, http://www.ipcc.ch/report/ar5/syr/ https://doi.org/10.1017/CBO9781107415416

Jarvis, MD 2014, 'The Black Box of Bureaucracy: Interrogating Accountability in the Public Service', Australian Journal of Public Administration, vol. 73, no. 4, pp. 450-466. https://doi.org/10.1111/1467-8500.12109

Keskitalo, ECH, Juhola, C, Baron, N, Fyhn, H \& Klein, J 2016, 'Implementing Local Climate Change Adaptation and Mitigation Actions: The Role of Various Policy Instruments in a Multi-Level Governance Context', Climate, vol. 4, no. 1, pp. 7-17. https://doi.org/10.3390/cli4010007

Kloot, L \& Martin, J 2001, 'Local government accountability: explaining differences', Accounting, Accountability \& Performance, vol. 7, no. 1, pp. 51-72.

Kramarz, T \& Park, S 2016, 'Accountability in Global Environmental Governance: A Meaningful Tool for Action?', Global Environmental Politics, vol. 16, no.3, pp. 1-21. https://doi.org/10.1162/GLEP a 00349

Lehman, G \& Kuruppu, S 2017, 'A framework for social and environmental accounting research', Accounting Forum, vol. 41, no. 3, pp.139-146. https://doi.org/10.1016/j.accfor.2017.07.001

Lewis, L \& Russell, S 2011, 'Permeating Boundaries: Accountability at the Nexus of Water and Climate Change', Social and Environmental Accountability Journal, vol. 31, no. 2, pp.117-123. https://doi.org/10.1080/0969160X.2011.593812

MacDonald, K 2014, 'The meaning and purposes of transnational accountability', Australian Journal of Public Administration, vol. 73, 
Quayle, Sciulli \& Wilson-Evered | Accountable to who, to whom, for what and how?

no. 4, pp. 426-436.

https://doi.org/10.1111/1467-8500.12107

Mees, H 2017, 'Local governments in the driving seat? A comparative analysis of public and private responsibilities for adaptation to climate change in European and North-American cities', Journal of Environmental Policy \& Planning, vol. 19, no. 4, pp.374-390. https://doi.org/10.1080/1523908X.2016.1223540

Mees, H \& Driessen, P 2018, 'A framework for assessing the accountability of local governance arrangements for adaptation to climate change', Journal of Environmental Planning and Management, vol. 62, no. 4, pp.671-691. https://doi.org/10.1080/09640568.2018.1428184

Milne, MJ \& Grubnic, S 2011, 'Climate Change Accounting Research: Keeping It Interesting and Different', Accounting Auditing \& Accountability Journal, vol. 24, no. 8, pp. 948-977.

https://doi.org/10.1108/09513571111184715

Mulgan, R 2000, 'Accountability: An Ever-Expanding Concept?', Public Administration, vol. 78, no. 3, pp.555-573. https://doi.org/10.1111/1467-9299.00218

Mulgan, R. (2003). Holding power to account, Palgrave Macmillan, London. https://doi.org/10.1057/9781403943835

Nelson, D, Adger, W \& Brown, K 2007, 'Adaptation to Environmental Change: Contributions of a Resilience Framework', Annual Review of Environment and Resources, vol. 32, no. 1, pp.395-419. https://doi.org/10.1146/annurev.energy.32.051807.090348

Newell, P 2008, 'Civil Society, Corporate Accountability and the Politics of Climate Change', Global Environmental Politics, vol. 8, no. 3, pp.122153. https://doi.org/10.1162/glep.2008.8.3.122

Parker, L 2011, 'Building Bridges to the Future: Mapping the Territory for Developing Social and Environmental Accountability'. Social and Environmental Accountability Journal, vol. 31, no. 1, pp. 7-24. https://doi.org/10.1080/0969160X.2011.556389

Perey, R 2013, 'Making sense of sustainability through an individual interview narrative', Culture and Organization, vol. 21, no. 2, pp.147173. https://doi.org/10.1080/14759551.2013.819354

Productivity Commission 2012, Barriers to Effective Climate Change Adaptation (Report No. 59, Final Inquiry Report), viewed 9 January 2016, http://www.pc.gov.au/inquiries/completed/climate-changeadaptation/report

Qu, SQ \& Dumay, J 2011, 'The qualitative research interview', Qualitative Research in Accounting \& Management, vol. 8, no. 3, pp238-264. https://doi.org/10.1108/11766091111162070 
Schedler, A 1999 'Conceptualizing Accountability', in A Schedler, L Diamond \& MF Plattner (eds), The Self-Restraining State: Power and Accountability in New Democracies, Lynne Rienner, Boulder, pp. 13 28.

Schillemans, T 2015, 'Managing Public Accountability: How Public Managers Manage Public Accountability', International Journal of Public Accountability, vol. 38, no. 6, pp. 433-441. https://doi.org/10.1080/01900692.2014.949738

Sciulli, N 2013. 'Organisational barriers to adapting infrastructure assets to climate change: Evidence from coastal councils in Australia', Public Money \& Management, vol. 33, no. 2, 153-160. https://doi.org/10.1080/09540962.2013.763436

Sullivan, R \& Gouldson, A 2013, 'Ten years of corporate action on climate change: What do we have to show for it?', Energy Policy, vol. 60, pp.733-740.

https://doi.org/10.1016/j.enpol.2013.05.025

Thomson, I, Grubnic, S \& Georgakopoulos, G 2014, 'Exploring accountingsustainability hybridisation in the UK public sector', Accounting, Organisations and Society, vol. 39, no. 6, pp. 453-476. https://doi.org/10.1016/j.aos.2014.02.003

Van den Berg, M \& Coenen, F 2012, 'Why tackle a far-off problem? Municipal resistance to climate change adaptation from an organisational change perspective', Workshop on Barriers to Adaptation to Climate Change, Berlin, 18-21 September 2012, viewed 18 May 2015, https://research.utwente.nl/en/publications/why-tacklea-far-off-problem-municipal-resistance-to-climate-chan

Van Dijk, A \& Summers, D, 2016, Australia's Environment Explorer, The Australian National University, viewed 21/10/19, http://wald.anu.edu.au/australias-environment/.

Yin, R 1994, Case study research: Design and methods (2nd ed.), Sage Publishing, Thousand Oaks, CA.

Zeemering, ES 2018, 'Sustainability management, strategy and reform in local government', Public Management Review, vol. 20, no. 1, pp. 136-153.

https://doi.org/10.1080/14719037.2017.1293148 